\title{
A IMPARCIALIDADE EM JOHN STUART MILL: UMA VIRTUDE JUDICIAL
}

\author{
The Impartiality in John Stuart Mill: a judicial virtue
}

\section{Everton Miguel Puhl Maciel *}

Resumo: O presente artigo explora a ideia de imparcialidade na teoria política de John Stuart Mill. Trata-se de uma virtude judicial importante na história do liberalismo inglês por oferecer uma chave de leitura inédita à dicotomia da liberdade como diametralmente oposta à igualdade, aqui entendida do ponto de vista político e judicial. Vamos discorrer sobre o problema tentando respeitar os parâmetros do utilitarismo clássico administrado ao longo de toda a obra Utilitarianism. Tentaremos mostrar que a imparcialidade está para o ambiente judicial da mesma forma que o conceito de igualdade para o ambiente político liberal. Defendemos que a imparcialidade representa algum tipo de sanção interna, como uma exigência moral, reclamada somente quando nosso dever é exigido publicamente. A conclusão indicará fatos e valores como pertencentes ao mesmo modelo teórico, sem a possibilidade de se estabelecer um rompimento entre prescritivismo e descritivismo na construção de uma teoria moral com essas características.

Palavras-chave: Justiça, Liberalismo, Imparcialidade, Democracia, Utilitarismo.

\begin{abstract}
This article explores the idea of impartiality as found in John Stuart Mill's political theory. Impartiality is an important judicial virtue in the history of English Liberalism and offers a new key to understand the dichotomy problem of liberty as diametrically opposed to equality, from the political and judicial point of view. We discuss the problem trying to respect the parameters of classical utilitarianism, as proposed throughout Mill's Utilitarianism. We shall argue that impartiality relates to the judicial environment in the same way equality relates to the liberal, political environment. We therefore support impartiality as some kind of internal sanction or moral demand, summoned when our duty is demanded in a public environment. In doing so, we aim to defend facts and values as belonging to the same theoretical model, excluding the possibility of severance between prescriptivism and descriptivism in building a moral theory with these features.
\end{abstract}

Keywords: Justice, Liberalism, Impartiality, Democracy, Utilitarianism.

* Doutorando em Filosofia PUCRS/Capes. Este trabalho não seria possível sem o apoio teórico dos professores John Skorupski e Hallvard Lillehammer (Birkbeck, University London); meu sincero agradecimento a ambos.

\begin{tabular}{|c|c|l|l|c|c|}
\hline intuitio & $\begin{array}{c}\text { ISSN } \\
1983-4012\end{array}$ & Porto Alegre & Vol.8 $-\mathrm{N}^{\mathrm{o} .2}$ & $\begin{array}{c}\text { Dezembro } \\
2015\end{array}$ & p.43-55 \\
\hline
\end{tabular}




\section{Introdução}

Barry Clark e John Elliott mostraram que o utilitarismo de John Stuart Mill não é autocontraditório, explorando justamente a ideia central de que o inglês do século XIX absorveu, em seu tempo, uma teoria da justiça para fazer frente a modelos semelhantes que caíam em descrédito. O motivo central da falência das teorias da justiça foi justamente sua inaplicabilidade prática, uma vez que a ideia de direito natural estava sendo explorada para frear o movimento emancipatório político das classes trabalhadoras e, ao mesmo tempo, o lucro daqueles que detinham os meios de produção, como observam os comentadores:

Teorias da justiça baseadas no direito natural caem em descrédito porque se colocam como barreiras potenciais aos interesses de ambos: classes de trabalhadores e proprietários. Da perspectiva dos proprietários, direitos naturais forneceram uma base potencial para a repressão moral e política na busca do lucro. Trabalhadores, por outro lado, poderiam ver os direitos naturais como esforços para vetar a reforma progressiva das instituições existentes ${ }^{1}$.

É nesse sentido que a conclusão do Utilitarianism com um escrito sobre a justiça busca elucidar as aparentes inconsistências dos outros trabalhos de Mill, especialmente, um potencial conflito entre seu modelo apresentado em On Liberty, anos antes, e a igualdade pública exigida pelo princípio da utilidade. Nesse artigo vamos explorar o conceito de imparcialidade do ponto de vista jurídico, um pilar fundamental do constructo teórico desenvolvido por Mill.

\section{Imparcialidade}

Nada mais próximo da igualdade política do que a imparcialidade judicial. Pretendemos agora elucidar o problema da imparcialidade por dois motivos: primeiramente, trata-se de um elemento pouco explorado e de suma importância para a filosofia de Mill; em segundo lugar, ele pode ser a chave para a solução de problemas importantes, como a aparente incongruência dos conceitos de igualdade e liberdade, o principal problema da história do liberalismo. Visualizaremos a questão da imparcialidade sem deixar de lado nosso problema mais amplo da justiça e o utilitarismo que Mill advogou como um todo. Apenas com esses três elementos, podemos ir para o passo seguinte e compreender o método do autor que envolve tanto a prescritividade quanto a descritividade do liberalismo contemporâneo.

O utilitarismo de Mill é radicalmente distante do contratualismo do seu tempo no seguinte sentido: está preocupado com uma justificação moral que precisa ser necessariamente discutida, quando não

\footnotetext{
1 "Teories of justice based on natural rights fell into disrepute because they posed potential barriers to the interests of both owning and laboring classes. From the perspective of owners, natural rights provided a potencial basis for moral and political restraint on the pursuit of profit. Workers, on the other hand, could view natural rights as blocking efforts for progressive reform of existing institutions" (CLARK, B. S.; ELLIOTT, J. E. John Stuart Mill's Theory of Justice. Review of Social Economy. London: Taylor \& Francis, v.59, n.4, dez., 2001, p.469).
}

\begin{tabular}{|c|c|l|l|c|c|}
\hline intuitio & $\begin{array}{c}\text { ISSN } \\
1983-4012\end{array}$ & Porto Alegre & Vol.8 $-\mathrm{N}^{\mathrm{o} .2}$ & $\begin{array}{c}\text { Dezembro } \\
2015\end{array}$ & p.43-55 \\
\hline
\end{tabular}


completamente elaborada, dentro do ambiente democrático. Isso acontece especialmente em virtude do tipo de espaço propício para a conveniência geral oferecido em ambientes plurais.

Uma das alternativas é abordar o problema pelo critério judicial da imparcialidade, uma virtude judicial que ocupa um espaço especial nos tribunais, mas sem uma aplicação necessária na vida privada dos indivíduos. A teoria da utilidade de Mill precisa ser entendida como um critério que visualiza a felicidade do gênero humano como a única coisa desejável em si mesma. Para trabalhar sua compreensão de um conceito mais amplo de utilitarismo, Mill precisa ter em vista uma normatividade judicial capaz de arbitrar a promoção da felicidade. Nas palavras do autor, como vimos: "o credo que admite a Utilidade, ou Princípio da Maior Felicidade, como o fundamento da moral sustenta que as ações são corretas na proporção com que tendem a promover a felicidade, e erradas quando elas tendem a produzir o contrário de felicidade" ${ }^{2}$.

Aquilo que Mill denomina de "credo" tem um sentido bastante peculiar, e diz respeito a acreditar em toda a teoria utilitarista. A escolha da palavra creed exige-nos um esforço para compreender o utilitarismo de Mill observando que ele trabalha com uma filosofia de método endoxal em um sentido bastante particular: o autor, por vezes, se alterna em justificar o princípio da utilidade tanto do ponto de vista do senso comum, quanto repousa sua argumentação em um esclarecimento racional obtido através de uma reflexão mais cuidadosa e menos popular. "Creed" não passa de uma palavra resgatada do senso comum, mesmo que a justificação do princípio da utilidade tenha uma origem mais profunda e reflexiva ${ }^{3}$. O princípio da maior felicidade, ou princípio da utilidade, é estabelecido tendo em vista alguns pressupostos: desde a noção histórica de Mill, fazendo frente ao positivismo de Augusto Comte, até o princípio da liberdade, promotor de uma teoria polêmica envolvendo a irrestrita liberdade de opinião ${ }^{4}$, mas ratificado por teóricos liberais contemporâneos ${ }^{5}$. A felicidade tem características muito amplas e, além disso, admite um pluralismo irrestrito para a compreensão e aplicação do termo. Essa pluralidade repousa justamente na noção abrangente das relações sociais com as quais os utilitaristas clássicos trabalharam

\footnotetext{
2 "The creed which accepts as the foundation of morals, Utility, or the Greatest Happiness Principle, holds that actions are right in proportion as they tend to promote happiness, wrong as they tend to produce the reverse of happiness" (CW X:210).

${ }^{3}$ Esse método de trabalho é mais facilmente observado nos Three Essays on Religion (CW X:369), especialmente quando Mill aborda a questão de um "criador", permanentemente, no sentido religioso atribuído historicamente ao termo. Em parte, o "credo" no princípio da utilidade pode servir para desbaratar críticos como Bernard Williams, para quem o utilitarista indireto não deve acreditar em sua própria teoria, se ele mesmo estiver certo (WILLIAMS, B. Moral: uma introdução à ética. São Paulo: Martins Fontes, 2005, p.137s).

${ }^{4}$ BOUTON, C. W. John Stuart Mill: on liberty and history. The Western Political Quarterly. Salt Lake City: University of Utah, v.18, n.3, set., 1965, p.569s.

${ }^{5}$ Ronald Dworkin, por exemplo, pertence à corrente crítica ao utilitarismo que busca a sobreposição da justiça frente ao bem. No entanto, ele advoga a favor dos princípios de liberdade pregados pelo movimento utilitarista inglês, especialmente a partir de Mill (DWORKIN, R. Levando os Direitos a Sério. Tradução: Nelson Boeira. São Paulo: Martins Fontes, 2002, p.399ss).
}

\begin{tabular}{|c|c|l|l|c|c|}
\hline intuitio & $\begin{array}{c}\text { ISSN } \\
1983-4012\end{array}$ & Porto Alegre & Vol.8 $-\mathrm{N}^{\mathrm{o} .2}$ & $\begin{array}{c}\text { Dezembro } \\
2015\end{array}$ & p.43-55 \\
\hline
\end{tabular}


incansavelmente. Teorias com essa característica foram mal interpretadas por muitos contemporâneos, como bem observa Esperanza Guisán:

como se os críticos contemporâneos nunca tivessem lido Bentham, e supostamente ignorassem totalmente Mill, começaram a computar no utilitarismo a falta daquilo, precisamente, que consistiu a razão de ser do pensamento utilitarista clássico, a saber: a defesa do indivíduo particular, os interesses individuais, a liberdade, a igualdade ou alcançar uma sociedade mais justa ${ }^{6}$.

A teoria da justiça proposta por Mill é conveniente. Esse termo, algumas vezes intercambiável com "útil", pode ajudar a elucidar potenciais inconsistências na proposta abrangente do utilitarismo clássico $^{7}$. É por meio da compreensão de justiça do autor que poderemos visualizar objetivamente o critério de imparcialidade, a primeira e mais importantes das virtudes judiciais ${ }^{8}$; e que ocupa um lugar de destaque justamente pela necessidade do estabelecimento de um elemento de administração judicial que responda às necessidades utilitaristas de conveniência. $\mathrm{O}$ critério é tão importante do ponto de vista político quanto a liberdade individual, especialmente quando levamos em conta a importância que Mill conferia à manutenção da estabilidade social. A justiça, em hipótese alguma, tem valor em si mesma. Nas palavras do próprio Mill:

O sentimento poderoso, e percepção aparentemente clara, que essa palavra [justiça] recorda, com agilidade e certeza que se assemelham a um instinto pareceu, para muitos pensadores, apontar para uma qualidade inerente às coisas; mostrar que o Justo pode ter uma existência na Natureza como algo absoluto genericamente distinto de toda variedade de Conveniência, e, em ideia, oposta a essa, embora (como é comumente conhecido), a longo prazo, nunca de fato desconexo dela [a utilidade, felicidade ou, neste caso, conveniência] ${ }^{9}$.

Muito distante de ter uma qualidade em si mesma, a justiça utilitarista está submetida à conveniência social, e ela não encontra pontos fixos independentes para normatizar as condutas de uma comunidade. Mais tarde, falaremos de uma justificação política para a justiça utilitarista do autor. Por ora, precisamos observar que Mill dedica poucas palavras para uma descrição analítica do conceito de justiça. O restante de sua preocupação é normativa e ele deixa clara a impossibilidade de tratar a filosofia utilitarista como meramente deontológica, na medida que Mill coloca limites aos atos envolvendo louvor e

\footnotetext{
${ }^{6}$ GUISÁN, E. Esperando por Mill. Tradução: Rita de Cássia Lana. In PELUSO, Luiz Alberto (org). Ética \& Utilitarismo. Campinas: Alínea, 1998, p.113.

${ }^{7}$ Esse conceito será nosso objeto de estudo na parte 3.2 deste trabalho: "A Justiça e a Conveniência".

${ }^{8} \mathrm{CW} \mathrm{X:257.}$

9 "The powerful sentiment, and apparently clear perception, which that word recals with a rapidity and certainty resembling an instinct, have seemed to the majority of thinkers to point to an inherent quality in things; to show that the Just must have an existence in Nature as something absolute - generically distinct from every variety of the Expedient, and, in idea, opposed to it, though (as is commonly acknowledged) never, in the long run, disjoined from it in fact" (CW X:240).
}

\begin{tabular}{|c|c|c|c|c|c|}
\hline intuitio & $\begin{array}{c}\text { ISSN } \\
1983-4012\end{array}$ & Porto Alegre & Vol.8 $-\mathrm{N}^{\circ} .2$ & $\begin{array}{c}\text { Dezembro } \\
2015\end{array}$ & p.43-55 \\
\hline
\end{tabular}


censura. Trata-se de uma chave importante para a distinção entre a moralidade e a mera conveniência ${ }^{10}$, uma parte da noção geral de dever que pode representar uma obrigatoriedade em alguns casos.

Mesmo com tantos elementos que tornam a imparcialidade indispensável no âmbito judicial, não podemos considerar como dever de uma pessoa muito mais do que podemos exigir dela. Até aqui temos uma deontologia, mas não tão reguladora que seja capaz de arbitrar todos os aspectos da vida. A justiça, em Mill, diz respeito apenas ao ambiente onde há a necessidade de se reclamar obrigações com essas características, ou seja: publicamente.

Mill admite que a justiça é diferente dos outros ramos da moral, uma vez que envolve, em alguma medida, situações de generosidade e beneficência, por exemplo. Ele visualiza essas condutas sociais no ramo dos deveres perfeitos, quando direitos estão envolvidos, uma vez que nossos esforços devem se voltar para garantir todo o bem que possamos fornecer à humanidade em geral, e não a um determinado indivíduo específico. Essa característica é particularmente importante na teoria da justiça de Mill, uma vez que podemos extrair dela o problema da imparcialidade com muita riqueza de detalhes. Mesmo sem um alicerce independente da utilidade, a superioridade prática da justiça autoriza Mill a estabelecer uma definição dela pelo conceito de bem-estar social:

Justiça é um nome para certas classes de regras morais que concernem ao essencial do bem-estar humano, e são, portanto, de obrigação mais absoluta do que quaisquer outras regras que servem para a orientação da vida; e a noção que nós temos defendido ser a essência da ideia de justiça, de um direito que reside em um indivíduo, implica e atesta em favor dessa obrigação compulsória ${ }^{11}$.

A justiça fica sendo, assim, uma definição apropriada para algumas regras ligadas àquilo que é socialmente conveniente, mais amplas, imperativas e, do ponto de vista da legislação positiva, compulsórias. Nesse contexto, a imparcialidade, no âmbito judicial, é uma obrigação moral ampla e basilar. Não se trata da única das virtudes judiciais, mas é uma condição necessária para o cumprimento dessas obrigações de justiça ${ }^{12}$. Em Mill, o elemento da imparcialidade não diz respeito a tudo na vida, uma vez que é reclamado em situações específicas, quando se espera o respeito à utilidade social. A imparcialidade não pode ser exigida independente da conveniência. Nada pode nos exigir que tenhamos um comportamento imparcial nas nossas relações privadas, sejam elas familiares ou de amizade. No entanto, reconhecemos que, em uma sociedade cooperativa e com associação industrial, a distribuição dos

\footnotetext{
${ }^{10} \mathrm{CW} \mathrm{X:246.}$

11 "Justice is a name for certain classes of moral rules, which concern the essentials of human well-being more nearly, and are therefore of more absolute obligation, than any other rules for the guidance of life; and the notion which we have found to be of the essence of the idea of justice, that of a right residing in an individual, implies and testifies to this more binding obligation" (CW X:255).

${ }^{12}$ CW X:257.
}

\begin{tabular}{|c|c|c|c|c|c|}
\hline intuitio & $\begin{array}{c}\text { ISSN } \\
1983-4012\end{array}$ & Porto Alegre & Vol.8 $-\mathrm{N}^{\mathrm{o}} .2$ & $\begin{array}{c}\text { Dezembro } \\
2015\end{array}$ & p.43-55 \\
\hline
\end{tabular}


bens deve ser submetida à conveniência e autorizamos uma remuneração superior ou inferior aos diferentes trabalhadores de acordo com esse critério ${ }^{13}$.

Independente das considerações que podem ser articuladas para atribuir à imparcialidade a característica de um princípio abstrato ou relativista, Mill se precaveu dessa imprecisão fazendo com que esse "princípio abstrato da justiça social" repousasse sobre um fundamento ainda mais profundo, compreendido no próprio significado da palavra utilidade ${ }^{14}$. O problema da imparcialidade é visto por Clark e Elliott como uma alternativa indispensável para a compreensão daquilo que chamam de "princípio

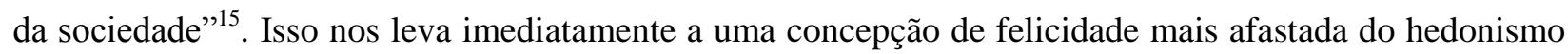
tradicional e nos obriga a uma distinção entre uma mera concepção de bem-estar, do ponto de vista dos bens primários, e uma noção mais abrangente do termo que pode ser entendido como um "hedonismo qualitativo" ". A visível influência romântica de Mill atesta essa possibilidade, seja pelos seus relatos autobiográficos ou, como observa Roger Crisp, pela influência da poesia e da filosofia antiga, um ponto de afastamento da filosofia de Bentham, unicamente influenciada pelo modelo científico:

um hedonista acredita que o bem-estar consiste em experiências aprazíveis. Mas isso deixa em aberto a questão do que $f a z$ experiências boas aprazíveis. Aquilo que chamarei de estados de hedonismo completo que faz essas experiências boas para alguém não é, digamos, que Deus goste que elas existam, ou que elas cumpram certos desejos de uma pessoa, mas apenas que elas são aprazíveis ${ }^{17}$.

A partir desse passo oferecido ao hedonismo diante da leitura de Mill, Crisp divide o chamado hedonismo completo em dois componentes, um substantivo e outro explanatório. O primeiro trata do hedonismo tanto de Bentham quanto de Mill, e é uma característica comum a qualquer teoria hedonista: afirma que o bem-estar consiste em experiências agradáveis; o segundo, a distinção real da filosofia oferecida por Mill, garante que aquilo que torna boa uma experiência agradável é o simples fato de ela ser aprazível. Trata-se de uma característica subjetiva, diante da objetividade oferecida pelo externalismo hedonista. O problema reside no fato de Mill ter contrastado prazer e dor e não feito uma distinção entre o

\footnotetext{
${ }^{13}$ CW X:253s.

${ }^{14} \mathrm{CW} \mathrm{X:257.}$

${ }^{15}$ Essa característica da teoria da justiça de Mill deve ser observada em harmonia com o princípio da utilidade e o princípio do progresso (CLARK, B. S.; ELLIOTT, J. E. John Stuart Mill's Theory of Justice. Review of Social Economy. London: Taylor \& Francis, v.59, n.4, dez., 2001, p.473). Apesar da reconhecida importância da ideia de progresso em Mill, por ora, vamos tratar do tema apenas superficialmente. O assunto será expandido no nosso capítulo 2.2: “A Democracia e a Justificação".

${ }^{16}$ CARVALHO, M. C M. de. Utilitarismo em Foco: um encontro com seus proponentes e críticos. Florianópolis: UFSC, 2007, p.83ss.

17 " [...] a hedonist believes that welfare consists in pleasurable experiences. But this leaves open the question what it is that makes pleasurable experiences good. What I shall call full hedonism states that what makes these experiences good for someone is not, say, that God likes them to exist, or that they fulfil certain desires of that person, but solely that they are pleasurable" (CRISP, R. Mill on utilitarianism. London: Routledge, 1997, p.26).
}

\begin{tabular}{|c|c|c|c|c|c|}
\hline intuitio & $\begin{array}{c}\text { ISSN } \\
1983-4012\end{array}$ & Porto Alegre & Vol.8 $-\mathrm{N}^{\mathrm{o}} .2$ & $\begin{array}{c}\text { Dezembro } \\
2015\end{array}$ & p.43-55 \\
\hline
\end{tabular}


conceito de prazer e um prazer específico, problema só levantado por Crisp, autorizando a leitura de um hedonismo completo, distinguindo o substantivo, um prazer, de noções de $\operatorname{prazer}^{18}$.

Essa concepção de felicidade é criticada por muitos teóricos contemporâneos, como é o caso de Terence Irwin, que observa problemas no fato de Mill desenvolver sua definição de prazeres mais elevados citando a quantidade de pessoas interessadas em determinada sensação ${ }^{19}$. No nosso próximo ponto, para analisar as questões de prescritivismo e descritivismo, compreenderemos como funciona a ideia de desejo em Mill, justamente para tentar resolver problemas como estes. Aqui nos interessa mostrar que uma concepção mais ampla de hedonismo garantiria elementos públicos de justiça, como a imparcialidade.

O importante nesse momento é compreender a passagem de um welfare state para um well-being que leva em conta uma noção geral de humanidade muito mais plausível dentro de um ambiente democrático como aquele que o autor já visualizava no séc. XIX. É na imparcialidade que esses elementos democráticos se congregam. Isso acontece porque fica claro que se trata de uma virtude reclamada muito especialmente em âmbito público, apenas quando a conveniência social exige:

é, por aceitação universal, inconsistente com a justiça ser parcial; mostrar favor ou preferência para uma pessoa em detrimento de outra, nas questões em que o favor e a preferencia não se aplicam propriamente. Imparcialidade, entretanto, não aparenta ser considerada como um dever em si mesmo, mas, antes disso, como um instrumento para algum outro dever; pois é reconhecido que favor e preferência não são sempre censuráveis e, de fato, os casos em que são condenáveis são a exceção em vez da regra. Uma pessoa provavelmente seria mais censurada que elogiada por não dar superioridade de auxílio a sua família ou amigos em detrimento de estranhos, quando puder fazê-lo sem violar algum outro dever; e ninguém pensa ser injusto procurar uma pessoa em preferência de outra como um amigo, colega ou companheiro. Imparcialidade, tratando-se de direitos, é, claro, obrigatória, mas isso envolve uma obrigação mais geral de dar a cada um o seu direito ${ }^{20}$.

A motivação de Mill para fazer novas considerações a respeito do conceito de justiça envolvia a polarização dos interesses de classes, como vimos na posição de Clark e Elliott. Os autores ultrapassam esse ponto, acrescentando que para a compreensão da teoria da justiça utilitarista é preciso incluir

\footnotetext{
${ }^{18}$ CRISP, R. Mill on utilitarianism. London: Routledge, 1997, p.26s.

${ }^{19}$ IRWIN, T. Mill: earlier utilitarianism and its critics / Mill: a revised version of utilitarianism. The Development of Ethics. v.3. New York: Oxford University Press, 2009, p.401.

20 " [...] it is, by universal admission, inconsistent with justice to be partial; to show favour or preference to one person over another, in matters to which favour and preference do not properly apply. Impartiality, however, does not seem to be regarded as a duty in itself, but rather as instrumental to some other duty; for it is admitted that favour and preference are not always censurable, and indeed the cases in which they are condemned are rather the exception than the rule. A person would be more likely to be blamed than applauded for giving his family or friends no superiority in good offices over strangers, when he could do so without violating any other duty; and no one thinks it unjust to seek one person in preference to another as a friend, connexion, or companion. Impartiality where rights are concerned is of course obligatory, but this is involved in the more general obligation of giving to every one his right" (CW X:243).
}

\begin{tabular}{|c|c|l|l|c|c|}
\hline intuitio & $\begin{array}{c}\text { ISSN } \\
1983-4012\end{array}$ & Porto Alegre & Vol.8 $-\mathrm{N}^{\mathrm{o}} .2$ & $\begin{array}{c}\text { Dezembro } \\
2015\end{array}$ & p.43-55 \\
\hline
\end{tabular}


implicitamente uma leitura das características subjetivas e objetivas, assim como uma "evolução adaptativa", importante, na nossa leitura, para uma compreensão positivista e naturalizada do modelo apresentado por Mill. Nas palavras dos autores:

Uma teoria liberal da justiça coerente, portanto, requer um critério objetivo congruente com os interesses dos cidadãos e, simultaneamente, um critério subjetivo que afirma as normas incorporadas nas instituições sociais. Essa dualidade foi reconhecida por John Locke que baseou os direitos de propriedade tanto na lei natural quanto no consentimento; e por Adam Smith que se apoiou não só na lei natural como também na aprovação. Jeremy Bentham apelou à utilidade como, ao mesmo tempo, subjetiva (i.e., prazeres experimentados por indivíduos) e objetiva (i.e., medida e comparada interpessoalmente) $)^{21}$.

O dualismo ao qual se referem os comentadores é previsto por Mill, em boa medida, no terceiro capítulo do Utilitarianism que antecede a ligação entre a justiça e a utilidade. O autor busca saber a que tipo de sanção última está submetido o princípio da utilidade. O título do capítulo prevê apenas uma sanção, no singular, "Sobre a Sanção Última do Princípio da Utilidade"22. O detalhe é que Mill a subdivide em elementos internos e externos. São essas "sanções", muitas vezes pertencentes a outros sistemas morais, como os diferentes modelos legislativos, que obrigam o agente moral a agir. As sanções internas são fáceis de serem reconhecidas. Segundo Mill,

são a esperança do favor e do medo do desprazer das criaturas que nos são próximas ou do Legislador do Universo, juntamente com quaisquer coisas pelas quais podemos ter simpatia ou afeição, amor ou mesmo temor por Ele, inclinando-nos a fazer a sua vontade independentemente de consequências egoístas. Não existe, evidentemente, razão para que todos esses motivos para a observância não deveriam se ligar à moral utilitarista, tão completamente e veementemente, como a qualquer outra ${ }^{23}$.

Neste trabalho, defendemos que a imparcialidade representa algum tipo de sanção interna, como uma exigência moral, reclamada quando nosso dever é exigido publicamente. Mill descreve o problema no parágrafo seguinte:

\footnotetext{
21 "A coherent liberal theory of justice thus requires an objective criterion congruent with the interests of citizens and, simultaneously, a subjective criterion that affirms the norms embodied in social institutions. This duality was recognized by John Locke, who based property rights on both natural law and consent, and by Adam Smith, who relied on both natural law and approbation. Jeremy Bentham appealed to utility as both subjective (i.e., pleasure experienced by individuals) and objective (i.e., measurable and interpersonally comparable)" (CLARK, B. S.; ELLIOTT, J. E. John Stuart Mill's Theory of Justice. Review of Social Economy. London: Taylor \& Francis, v.59, n.4, dez., 2001, p.471).

22 "Of the Ultimate Sanction of the Principle of Utility" (CW X:227).

23 " [They] are, the hope of favour and the fear of displeasure from our fellow creatures or from the Ruler of the Universe, along with whatever we may have of sympathy or affection for them, or of love and awe of Him, inclining us to do his will independently of selfish consequences. There is evidently no reason why all these motives for observance should not attach themselves to the utilitarian morality, as completely and as powerfully as to any other" (CW X:228).
}

\begin{tabular}{|c|c|l|l|c|c|}
\hline intuitio & $\begin{array}{c}\text { ISSN } \\
1983-4012\end{array}$ & Porto Alegre & Vol.8 $-\mathrm{N}^{\mathrm{o} .2}$ & $\begin{array}{c}\text { Dezembro } \\
2015\end{array}$ & p.43-55 \\
\hline
\end{tabular}


A sanção interna do dever, independente de nosso critério de dever, é apenas uma: um sentimento na nossa própria mente; uma dor, mais ou menos intensa, decorrente da violação do dever, o que propriamente faz com que as naturezas morais devidamente cultivadas progridam, em casos mais sérios, em um grau que as fazem recuar diante dessa agressão, como uma impossibilidade. Esse sentimento, quando desinteressado, e conectado à ideia pura de dever, e não com alguma forma particular dele, ou com nenhuma mera circunstância acessória, é a essência da Consciência $[\ldots]^{24}$.

Precisamos reconhecer um problema muito latente nesse ponto. Mill afirma que o princípio da utilidade é a "última solução de todas as questões éticas". Não se trata da mais importante, muito menos da mais relevante em todos os casos. A utilidade não é uma sanção, assemelha-se mais a um critério último de ajuizamento moral, importante para o ato de deliberar do agente. Apenas quando analisamos isso dentro dos padrões do utilitarismo hedonista estamos autorizados a fazer uma divisão entre sanções internas e externas. Por sanção devemos compreender algo que motiva o agente moral. O princípio da utilidade, isolado, não tem essa característica e deve ser inclusive administrado apenas indiretamente, nos casos em que há a necessidade de reclamar um critério mais profundo. Essa seria uma das principais características do chamado utilitarismo indireto, ou seja, o agente moral está preocupado com as sanções e não com o princípio da utilidade em si. Preocupada com o fator do hedonismo e as amplas faces da felicidade, Guisán observa esse problema com muita propriedade e indica o espaço que os elementos de prazer e dor ocupam na teoria de Mill:

o hedonismo é uma teoria inteligente que não cai nas inconsistências que os que não a compreendem lhe imputam. [...] O hedonismo significa que o prazer é o último critério moral, não é o único critério moral. $\mathrm{O}$ bem último, mas não o único bem ${ }^{25}$.

Se quisermos alguma resposta a respeito do último critério da moralidade, precisamos apresentar algumas informações sobre o comportamento humano. A ideia de moral evolutiva afirma que as sensações de dor e prazer podem mudar ao longo das gerações, mas o critério se mantém intacto. Podemos valorizar mais uma determinada sensação, como a de possuir um determinado recurso, quando ele é escasso ou o bem em questão é difícil de ser adquirido ou mantido. Mill admitia essa flexibilidade, da mesma forma que defendia um princípio da utilidade com desejos informados e conscientes. Absorver o modelo

\footnotetext{
24 "The internal sanction of duty, whatever our standard of duty may be, is one and the same - a feeling in our own mind; a pain, more or less intense, attendant on violation of duty, which in properly - cultivated moral natures rises, in the more serious cases, into shrinking from it as an impossibility. This feeling, when disinterested, and connecting itself with the pure idea of duty, and not with some particular form of it, or with any of the merely accessory circumstances, is the essence of Conscience [...]" (CW X:228).

25 “[...] el hedonismo es una teoría inteligente que no cae en las inconsitencias que los que no la comprenden le achacan. [...] El hedonismo significa que el placer es el último criterio moral, no el único criterio moral. El bien último, pero no el único bien" (GUISÁN, E. Manifesto Hedonista. Barcelona: Anthropos, 1990, p.22).
}

\begin{tabular}{|c|c|c|c|c|c|}
\hline intuitio & $\begin{array}{c}\text { ISSN } \\
1983-4012\end{array}$ & Porto Alegre & Vol.8 $-\mathrm{N}^{\mathrm{o} .2}$ & $\begin{array}{c}\text { Dezembro } \\
2015\end{array}$ & p.43-55 \\
\hline
\end{tabular}


utilitarista e o elemento da imparcialidade, presente com tanta força na sua teoria judicial, é também admitir uma descrição fina do comportamento humano ${ }^{26}$.

Quando tratamos das questões envolvendo a imparcialidade, logo nos vem à mente a imagem que ficou historicamente conhecida como "espectador imparcial". Mill inaugurou essa discussão na história da filosofia política contemporânea, no segundo capítulo do Utilitarianism. Naquele momento da sua teoria, ele não estava ainda preocupado com as questões judiciais, mesmo que já tivesse em mente a ideia de imparcialidade, alguns capítulos depois. Assim, podemos notar que o espectador imparcial, descrito como "desinteressado e benevolente", é articulado para fazer frente à noção de que devemos visualizar a moralidade na busca da felicidade para todos os envolvidos. Ora, isso está mais ligado à ideia de igualdade do que de imparcialidade. Na polêmica passagem, Mill sentencia o seguinte:

a felicidade, na forma que os utilitaristas adotam como critério de conduta, não é a felicidade do próprio agente, mas a de todos os envolvidos. Entre sua própria felicidade e a dos outros, o utilitarismo requer do agente ser estritamente imparcial, como um espectador desinteressado e benevolente ${ }^{27}$.

Para exemplificar o espectador desinteressado e benevolente, Mill não tem dúvidas ao utilizar um exemplo clássico e também, até certo ponto, curioso: Jesus Cristo. O pensamento evangelista "ames o outro como a si mesmo; faça ao próximo o que queres que te façam" ${ }^{\text {} 28}$ representa para o utilitarismo uma noção perfeita de comunhão entre a primeira e a terceira pessoa, sem nenhum artifício metafísico com sentido religioso. O que precisamos notar aqui, usando o exemplo proposto, é que, se Mill chama seu espectador de imparcial, também apresenta outros adjetivos a ele. O conceito de imparcialidade seria vazio, se desarmado da ideia normativa de que o agente deve se comportar desinteressadamente e a ideia descritiva da benevolência humana que deriva do sentimento de compaixão. Mesmo que possamos acusar a opinião de Mill de otimista em excesso com relação aos sentimentos oriundos da descrição utilitarista, a noção de espectador desinteressado e benevolente nos dá uma pista interessante de uma característica que precisa ser explorada no autor, a mediedade. Trata-se de um contraste interno ao próprio utilitarismo, uma vez que Bentham é um hedonista tradicional e Moore inaugurou o utilitarismo não-hedonista. Assim, Mill é classificado como utilitarista médio, como aponta Jack Smart:

Mill parecia ocupar uma posição intermediária. Estabeleceu que há prazeres mais altos e mais baixos. O que parece implicar que o prazer é uma condição para a

\footnotetext{
${ }^{26}$ CLARK, B. S.; ELLIOTT, J. E. John Stuart Mill's Theory of Justice. Review of Social Economy. London: Taylor \& Francis, v.59, n.4, dez., 2001, p.473.

27 " [...] the happiness which forms the utilitarian standard of what is fight in conduct, is not the agent's own happiness, but that of all concerned. As between his own happiness and that of others, utilitarianism requires him to be as strictly impartial as a disinterested and benevolent spectator" (CW X:218).

${ }^{28}$ Mt 19,19 e 7,12.
}

\begin{tabular}{|c|c|l|l|c|c|}
\hline intuitio & $\begin{array}{c}\text { ISSN } \\
1983-4012\end{array}$ & Porto Alegre & Vol.8 $-\mathrm{N}^{\mathrm{o} .2}$ & $\begin{array}{c}\text { Dezembro } \\
2015\end{array}$ & p.43-55 \\
\hline
\end{tabular}


bondade, mas que tal bondade depende de outras qualidades de experiências além da agradabilidade de desagradabilidade ${ }^{29}$.

Não há, em Mill, um nível de benevolência desmedido; como contraponto à benevolência há o egoísmo do agente moral que, por sua vez, é limitado pela conveniência social. Inclusive, é nesse ponto de equilíbrio entre os dois fatores descritivos do espectador imparcial que encontramos rescaldos da justiça em um sentido mais amplo. As pistas são semeadas pelo próprio Mill:

é um equivoco do modo de pensar do utilitarismo supor que as pessoas deveriam fixar sua mente em alguma coisa tão genérica como o mundo, ou a sociedade como um todo. A grande maioria das boas ações não pretende beneficiar o mundo, mas os indivíduos que fazem parte do bem do mundo; e os pensamentos do mais virtuoso dos homens não precisam, nesses casos, ir além das pessoas particulares envolvidas, a não ser que haja necessidade de se assegurar que, beneficiando-as, ele não viola os direitos - isto é, as expectativas autorizadas e legítimas - de nenhuma outra ${ }^{30}$.

Ora, como vimos, reside justamente na ideia de imparcialidade a noção média de que devemos dar a cada um aquilo que lhe compete, sendo essas as expectativas autorizadas e legítimas das quais Mill está falando. Expandir a felicidade é, para o autor, o objetivo de um utilitarismo que prioriza um modelo alicerçado na virtude do agente moral; e a mais destacada das virtudes judiciais, a imparcialidade, não poderia ficar fora desse intento. São raros os casos em que a felicidade pública realmente está em jogo. No geral, é na utilidade privada que reside o real interesse pela felicidade. Mill observa que apenas os homens nos quais as ações exercem uma influência na sociedade em geral precisam estar preocupados com um resultado tão amplo. Esses casos tratam da exceção e não da regra de conduta geral. Mesmo os magistrados, quando agem, não precisam ter em mente um objeto com abrangência universal. O princípio da utilidade que lhes serve de ferramenta trata da mediação de interesses privados que afeta a sociedade indiretamente. Seria insólito fazer isso desarmado do fator imparcialidade para casos como estes, em que o bem-estar público é colocado no centro da discussão.

\footnotetext{
29 “Mill parecía ocupar una posición intermedia. Estableció que hay placeres más altos y más bajos. Lo cual parece implicar que el placer es una condición para la bondad, pero que tal bondad depende de otras cualidades de experiencia además de la agradabilidad y desagradabilidad" (SMART, J. J. J. C.; WILLIAMS, B. Utilitarismo: pro y contra. Tradução: Jesus Rodriguez Marin. Madrid: Tecnos, 1981, p.21).

30 " [...] it is a misapprehension of the utilitarian mode of thought, to conceive it as implying that people should fix their minds upon so wide a generality as the world, or society at large. The great majority of good actions are intended, not for the benefit of the world, but for that of individuals, of which the good of the world is made up; and the thoughts of the most virtuous man need not on these occasions travel beyond the particular persons concerned, except so far as is necessary to assure himself that in benefiting them he is not violating the rights - that is, the legitimate and authorized expectations - of any one else" (CW X:220).
}

\begin{tabular}{|c|c|l|l|c|c|}
\hline intuitio & $\begin{array}{c}\text { ISSN } \\
1983-4012\end{array}$ & Porto Alegre & Vol.8 $-\mathrm{N}^{\mathrm{o} .2}$ & $\begin{array}{c}\text { Dezembro } \\
2015\end{array}$ & p.43-55 \\
\hline
\end{tabular}




\section{Considerações finais}

Mill sabia que não podemos apresentar uma resposta especial, fora do mundo material, para as questões de justiça. Mesmo que pudéssemos engendrar algo parecido, estaríamos agredindo as noções mais básicas do materialismo utilitarista. A solução para esse problema foi oferecer, como ponto de partida, o indivíduo e as leis psicológicas de associação que passam longe de representar uma alternativa contratualista e trazem informações importantes sobre o processo de sociabilidade entre humanos. Frank Thilly observa que não podemos ter uma noção mística de uma "alma social" ou um "espírito de humanidade":

A ênfase que Mill coloca sobre o indivíduo não apenas o salva do determinismo ambiental professado por alguns sociólogos modernos, mas também tornou impossível a noção mística de uma alma social ou um espírito de humanidade flutuando sobre as almas individuais. Não havia espaço, em sua filosofia, para algo além de indivíduos de carne e osso, ou antes: um esqueleto psicológico ou uma estrutura de tais seres. Além disso, ele exercitava muita cautela em relação à concepção de sociedade como um organismo; ele fez uso de uma analogia de organismo, mas geralmente de uma maneira muito mecânica, na sua doutrina consensual, um termo que ele tomou emprestado da ciência fisiológica de seu tempo $^{31}$.

Mesmo assim, existem, na teoria de Mill, elementos comuns tão enraizados na nossa conduta social ordinária que nos levam a uma concepção menos individualista da sociedade. Para Thilly, são dois: a educação e o sentimento de lealdade ${ }^{32}$. Esses elementos não representam uma resposta especial para a questão. Na visão de Mill, podemos dizer que são fatos empíricos e verificáveis. Se não conhecêssemos nosso desejo de agregar às nossas vidas conforto material, por exemplo, não poderíamos ter como resultado a civilização. Segundo Thilly:

Sem conhecimento, o desejo por conforto material não teria produzido nossa civilização material; sem isso, as propensões egoístas divergentes não poderiam ter sido controladas. A existência social é possível apenas por disciplinar estas propensões poderosas, i,e., subordinando-as a um sistema comum de opiniões ${ }^{33}$.

\footnotetext{
31 "The stress which Mill laid upon the individual not only saved him from the environmental determinism taught by some modern sociologists, but made impossible the mystical notion of a social soul or a spirit of humanity floating over and above the individual souls. There was no place in his philosophy for anything but flesh and blood individuals, or, rather, the psychological skeleton or frame-work of such beings. Moreover, he exercised great caution with regard to the conception of society as an organism; he did make use of the analogy of the organism, but generally in quite a mechanical way, in his doctrine of the consensus, a term which he borrowed from the physiological science of his day" (THILLY, F. The Individualism of John Stuart Mill. The Philosophical Review. Durham: Duke University Press, v.32, n.1, jan., 1923, p.6).

${ }^{32}$ THILLY, F. The Individualism of John Stuart Mill. The Philosophical Review. Durham: Duke University Press, v.32, n.1, jan., 1923, p.8.

33 "Without knowledge the desire for material comfort would not have produced our material civilization; without it the disuniting selfish propensities could not have been curbed. Social existence is possible only by disciplining these
}

\begin{tabular}{|c|c|l|l|c|c|}
\hline intuitio & $\begin{array}{c}\text { ISSN } \\
1983-4012\end{array}$ & Porto Alegre & Vol.8 $-\mathrm{N}^{\mathrm{o} .2}$ & $\begin{array}{c}\text { Dezembro } \\
2015\end{array}$ & p.43-55 \\
\hline
\end{tabular}


O permanente desenvolvimento da questão educacional é um fato-valor na medida em que constatamos a melhora do convívio social, a partir de pessoas mais instruídas. Assim é possível compreender porque Mill valorou os desejos intelectuais como mais dignos de apreço que os desejos corpóreos quando observamos que sua teoria também é descritiva nesse ponto. Se fôssemos capazes de encontrar algum teórico contemporâneo que menosprezasse o conhecimento ou atribuísse algum descrédito à educação formal, poderíamos menosprezar a tese do hedonismo qualitativo de Mill. No entanto, o conceito é fundamental para que possamos compreender, inclusive, os problemas mais complexos que tratam das questões de justiça, como é o caso da imparcialidade. Sem a valoração positiva dessa qualidade judicial, o sentimento de lealdade, ao qual Thilly se refere, não seria importante para a compreensão da relação que a justiça tem com o princípio da utilidade.

\section{Referências}

MILL, J. S. Utilitarianism / Three Essays on Religion et al. In: Collected Works, v.10. Toronto: Toronto University Press; ROBSON, John (Ed.), 1969.

. On Liberty. In: Collected Works, v.18. Toronto University Press; ROBSON, John (Ed.), 1977.

BOUTON, C. W. John Stuart Mill: on liberty and history. The Western Political Quarterly. Salt Lake City: University of Utah, v.18, n.3, set., 1965, pp.569-578.

CARVALHO, M. C M. de. Utilitarismo em Foco: um encontro com seus proponentes e críticos. Florianópolis: UFSC, 2007.

CLARK, B. S.; ELLIOTT, J. E. John Stuart Mill's Theory of Justice. Review of Social Economy. London: Taylor \& Francis, v.59, n.4, dez., 2001, pp.467-490.

CRISP, R. Mill on utilitarianism. London: Routledge, 1997.

DWORKIN, R. Levando os Direitos a Sério. Tradução: Nelson Boeira. São Paulo: Martins Fontes, 2002.

GUISÁN, E. Esperando por Mill. Tradução: Rita de Cássia Lana. In PELUSO, Luiz Alberto (org). Ética \& Utilitarismo. Campinas: Alínea, 1998, pp111-130.

. Manifesto Hedonista. Barcelona: Anthropos, 1990.

IRWIN, T. Mill: earlier utilitarianism and its critics / Mill: a revised version of utilitarianism. The Development of Ethics. v.3. New York: Oxford University Press, 2009, pp.364-425.

SKORUPSKI, J. Why Read Mill Today? Routledge: London, 2008.

SMART, J. J. J. C.; WILliAMS, B. Utilitarismo: pro y contra. Tradução: Jesus Rodriguez Marin. Madrid: Tecnos, 1981.

THILLY, F. The Individualism of John Stuart Mill. The Philosophical Review. Durham: Duke University Press, v.32, n.1, jan., 1923, pp.1-17.

WILLIAMS, B. Moral: uma introdução à ética. São Paulo: Martins Fontes, 2005.

Data de Submissão: 28/09/2014

Data de Aprovação: 09/11/2015

powerful propensities, i.e., by subordinating them to a common system of opinions" (THILLY, F. The Individualism of John Stuart Mill. The Philosophical Review. Durham: Duke University Press, v.32, n.1, jan., 1923, p.10).

\begin{tabular}{|c|c|l|l|c|c|}
\hline intuitio & $\begin{array}{c}\text { ISSN } \\
1983-4012\end{array}$ & Porto Alegre & Vol.8 $-\mathrm{N}^{\mathrm{o}} .2$ & $\begin{array}{c}\text { Dezembro } \\
2015\end{array}$ & p.43-55 \\
\hline
\end{tabular}

